OPEN ACCESS

Edited by:

Deirdre A. Cunningham,

Francis Crick Institute,

United Kingdom

Reviewed by:

Hayley Bullen,

Burnet Institute, Australia

Jack Adderley,

RMIT University, Australia

*Correspondence:

Anaiis Merckx

anais.merckx@parisdescartes.fr

Specialty section: This article was submitted to

Parasite and Host,

a section of the journal

Frontiers in Cellular and

Infection Microbiology

Received: 03 December 2020

Accepted: 23 February 2021

Published: 24 March 2021

Citation:

Chauvet M, Chhuon C, Lipecka J,

Dechavanne S, Dechavanne C,

Lohezic M, Ortalli M, Pineau D,

Ribeil JA, Manceau S, Le Van Kim C,

Luty AJF, Migot-Nabias F,

Azouzi S, Guerrera IC and Merckx A (2021) Sickle Cell Trait

Modulates the Proteome and

Phosphoproteome of Plasmodium

falciparum-Infected Erythrocytes.

Front. Cell. Infect. Microbiol. 11:637604.

doi: 10.3389/fcimb.2021.637604

\title{
Sickle Cell Trait Modulates the Proteome and Phosphoproteome of Plasmodium falciparum-Infected Erythrocytes
}

Margaux Chauvet ${ }^{1,2}$, Cerina Chhuon ${ }^{3}$, Joanna Lipecka ${ }^{3}$, Sébastien Dechavanne ${ }^{2,4,5}$ Célia Dechavanne ${ }^{1}$, Murielle Lohezic ${ }^{1}$, Margherita Ortalli, ${ }^{1,2}$, Damien Pineau ${ }^{1,2}$, Jean-Antoine Ribeil ${ }^{6}$, Sandra Manceau ${ }^{2,6}$, Caroline Le Van Kim ${ }^{2,4,5}$, Adrian J. F. Luty ${ }^{1}$, Florence Migot-Nabias ${ }^{1}$, Slim Azouzi ${ }^{2,4,5}$, Ida Chiara Guerrera ${ }^{3}$ and Anaïs Merckx ${ }^{1,2 *}$

1 Université de Paris, MERIT, IRD, Paris, France, ${ }^{2}$ Laboratoire d'Excellence GR-Ex, Paris, France, ${ }^{3}$ Université de Paris, Proteomics Platform Necker, Structure Fédérative de Recherche Necker, Inserm US24/CNRS, UMS3633, Paris, France, ${ }^{4}$ Université de Paris, Inserm, BIGR, Paris, France, ${ }^{5}$ Institut National de la Transfusion Sanguine, Paris, France, ${ }^{6}$ Biotherapy Department, Necker Children's Hospital, Assistance Publique-Hôpitaux de Paris, Paris, France

The high prevalence of sickle cell disease in some human populations likely results from the protection afforded against severe Plasmodium falciparum malaria and death by heterozygous carriage of $\mathrm{HbS}$. $P$. falciparum remodels the erythrocyte membrane and skeleton, displaying parasite proteins at the erythrocyte surface that interact with key human proteins in the Ankyrin $\mathrm{R}$ and 4.1R complexes. Oxidative stress generated by $\mathrm{HbS}$, as well as by parasite invasion, disrupts the kinase/phosphatase balance, potentially interfering with the molecular interactions between human and parasite proteins. $\mathrm{HbS}$ is known to be associated with abnormal membrane display of parasite antigens. Studying the proteome and the phosphoproteome of red cell membrane extracts from $P$. falciparum infected and non-infected erythrocytes, we show here that HbS heterozygous carriage, combined with infection, modulates the phosphorylation of erythrocyte membrane transporters and skeletal proteins as well as of parasite proteins. Our results highlight modifications of Ser-/Thr- and/or Tyr- phosphorylation in key human proteins, such as ankyrin, $\beta$-adducin, $\beta$-spectrin and Band 3 , and key parasite proteins, such as RESA or MESA. Altered phosphorylation patterns could disturb the interactions within membrane protein complexes, affect nutrient uptake and the infected erythrocyte cytoadherence phenomenon, thus lessening the severity of malaria symptoms.

Keywords: Plasmodium falciparum, hemoglobin S, erythrocyte, membrane phosphorylation, proteomics

Abbreviations: BCA, Bi-cinchoninic acid; BSA, Bovine serum albumin; CPDA, Citrate-phosphate-dextrose with adenine; ECL, Electrochemiluminescence; FASP, Filter aided sample preparation; FDR, False discovery rate; G6PD, Glucose-6-phosphate dehydrogenase; Hb, Hemoglobin; HO, Hoechst; HPLC, High-performance liquid chromatography; iRBCs, infected RBCs; LFQ, Label-free quantification; MACS, Magnetic-activated cell sorting; MCs, Maurer's clefts; MESA, Mature parasite-infected erythrocyte surface antigen; MS, Mass spectrometry; PCR-RFLP, Polymerase chain reaction - restriction fragments length polymorphisms; PfEMP1, Plasmodium falciparum erythrocyte membrane protein 1; RBCs, Red blood cells; RESA, Ring-infected erythrocyte surface antigen; ROM1, Rhomboid protease 1; Ser or S, Serine; TBS, Tris buffered saline; TFA, Trifluoroacetic acid; Thr or T, Threonine; Tyr or Y, Tyrosine. 


\section{INTRODUCTION}

Hemoglobin (Hb) S erythrocyte abnormality is due to a genetic mutation resulting from the replacement of a glutamate at the sixth position within the $\beta$-globin chain by a valine in normal $\mathrm{Hb}$ (HbA) (Flint et al., 1998). The homozygous carriage of $\mathrm{HbS}$ (HbSS) results in sickle cell disease (SCD) which has serious pathological consequences such as anemia and vaso-occlusive crises and can be life-threatening. SCD is highly prevalent in human populations living in malaria endemic areas. The highest frequencies of $\mathrm{HbS}$ homozygous and heterozygous forms are indeed observed in sub-Saharan Africa, the Middle East, and India, reaching up to 25\% (Migot-Nabias et al., 2000) and could result from the protection afforded by $\mathrm{HbS}$ heterozygous carriage (HbAS) against severe Plasmodium falciparum malaria-related symptoms and death without serious hematological disadvantage (Piel et al., 2010; Gonçalves et al., 2016). The HbAS genotype, commonly called sickle cell trait, is less clinically visible than the HbSS one.

$P$. falciparum asexual multiplication within human red blood cells (RBCs) leads to malaria symptoms. During this phase, $P$. falciparum exports proteins into the erythrocyte cytosol and membrane in order to remodel the host cell and allow it to prosper in this environment. Some of the most profound changes in infected erythrocytes comprise protrusions at the surface, termed "knobs", and vesicular cisternae in the RBC cytosol, called "maurer's clefts » (MCs). Export of proteins involves the remodeling of host actin by the parasite, to connect MCs and MCs-originated vesicles to the host cell cytoskeleton and membrane (Rug et al., 2014). Knobs display « P. falciparum erythrocyte membrane protein $1 »(P f E M P 1)$ that mediates the cytoadherence of infected RBCs (iRBCs) to microvascular blood vessel endothelium, thus preventing clearance of iRBCs by the spleen. The resulting obstruction of the microvasculature in the brain and other organs is considered to be one of the major contributors to the pathology associated with the most severe forms of malaria (Miller et al., 2002).

The molecular mechanisms of the protection conferred against severe malaria symptoms by abnormal $\mathrm{HbS}$ are still only partially understood and under active investigation. Previous studies showed that HbAS erythrocytes display impaired parasite-induced host actin reorganization and incompletely developed MCs, leading to reduced and impaired protein export (Cholera et al., 2008; Fairhurst et al., 2012). Furthermore, these RBCs display reduced amounts of adhesins which are aberrantly presented as they are anchored in enlarged and dispersed knobs, correlating with reduced cytoadherence capacity. Oxidative stress caused by $\mathrm{HbS}$ instability underlies the aberrant development of the parasite, insofar as an oxidative insult conferred to $\mathrm{HbAA}$ RBCs can promote the same phenotypic discrepancies (Cyrklaff et al., 2016).

The underlying erythrocyte membrane based-skeleton is known to play a major role in the function of the RBC membrane as well as in parasite knobs' organization. This cytoskeleton is physically linked to the membrane by vertical interactions at two key sites: the AnkyrinR and the 4.1R complexes (Mankelow et al., 2012). Abnormalities in erythrocyte membrane proteins have been observed in RBC disorders and are often associated with an increase of oxidative stress on proteins themselves or with perturbations in intracellular signaling pathways such as the balance between phosphatase/kinase functions (Pantaleo et al., 2010a). The phosphoproteome of the AnkyrinR complex and the erythrocyte membrane (George et al., 2010) is affected in HbSS RBCs. This altered phosphorylation of skeleton proteins may affect membrane deformability, increasing fragility and rigidity of the erythrocyte (George et al., 2010).

Both parasite infection and $\mathrm{HbS}$ promote oxidative stress in RBCs, which can subsequently modify the phosphorylative status of human and parasite proteins. Phosphorylation is indeed a key mechanism for parasite development and could be disturbed by HbS. Previous studies showed that the kinase/phosphatase equilibrium alteration could influence cytoadherence of iRBCs to endothelial receptors (Dorin-Semblat et al., 2019), erythrocyte membrane channel activities (Merckx et al., 2008) and membrane mechanical properties of iRBCs (Nunes et al., 2010). Therefore, we hypothesized that modulation of protein phosphorylation in iRBCs could be one mechanism underlying the relative protection conferred by HbS against malaria.

The present study has investigated the impact of heterozygous $\mathrm{HbS}$ carriage, as well as of $P$. falciparum infection, on the phosphorylative states of protein components of the erythrocyte cytoskeleton and membrane, and of parasite proteins. To this end, the phosphoproteome and the proteome of erythrocyte ghosts and parasite proteins from $P$. falciparum infected and non-infected homozygous $\mathrm{HbAA}$ and heterozygous $\mathrm{HbAS} \mathrm{RBCs}$ were analyzed by mass spectrometry after $\mathrm{TiO}_{2}$ enrichment, and by western blots.

The mass spectrometry analysis describes phosphorylation differences of both RBCs and parasite proteins. Those alterations concerned erythrocyte skeleton - interacting parasite proteins, erythrocyte transporters, membrane and skeletal proteins and could be involved in the regulation of molecular interactions within membrane protein complexes, such as the cytoadherence complex, and in the regulation of the functions of these proteins.

\section{MATERIALS AND METHODS}

\section{Blood Samples}

$\mathrm{HbAA}$ and HbAS erythrocytes were obtained from voluntary donors, after written informed consent obtained in accordance with the Declaration of Helsinki at Necker-Enfants-Malades hospital (Committee for the Protection of Persons $n^{\circ}$ DC 20142272). This study was approved and conducted according to institutional ethical guidelines of the National Institute for Blood Transfusion (INTS, Paris, France). Blood was collected in tubes containing citrate-phosphate-dextrose with adenine (CPDA). RBCs were then separated from plasma and leucocytes by three washings in RPMI 1640 medium (Gibco-ThermoFisher Scientific) and were stored maximum $24 \mathrm{hrs}$ at $4^{\circ} \mathrm{C}$ before use, or cryoconserved.

\section{DNA Extraction}

Genomic DNA was extracted from the donor's leucocytes with the DNeasy Blood and Tissue Kit (Qiagen). The concentration and 
the quality of DNA were evaluated by measuring the absorbance at $260 \mathrm{~nm}$ and $280 \mathrm{~nm}$ with a Nanodrop spectrophotometer.

\section{Hemoglobin Genotyping}

Hemoglobin genotypes were determined by polymerase chain reaction - restriction fragments length polymorphisms (PCR-RFLP) adapted from Badaut et al. (2015), and according to the GoTaqFlexi DNA Polymerase (Promega) manufacturer requirements.

\section{Plasmodium falciparum-Infected Erythrocyte Culture}

$P$. falciparum strain 3D7 was grown in vitro in human $\mathrm{HbAA}$ and HbAS erythrocytes according to the procedures of "Methods in Malaria Research" (https://www.beiresources.org/portals/2/ MR4/Methods_In_Malaria_Research-6th_edition.pdf) adapted from Trager and Jensen (1976). Briefly, infected erythrocytes were cultured in RPAS (RPMI-Albumax-Serum) medium (RPMI 1640 medium (Gibco) supplemented with 25 mM HEPES (Gibco), $2 \mathrm{mM}$ L-glutamine (Gibco), $0.05 \mathrm{mg} / \mathrm{ml}$ gentamicin (Gibco), 2\% human serum and $0.5 \%$ of Albumax). Cultures were maintained at $5 \%$ hematocrit in a gas mixture of $2 \% \mathrm{O}_{2}, 5.5 \%$ $\mathrm{CO}_{2}$ and $92.5 \% \mathrm{~N}_{2}$ and incubated at $37^{\circ} \mathrm{C}$. HbAA and $\mathrm{HbAS}$ RBCs from donors were infected with late trophozoite and schizont-infected HbAA erythrocytes obtained after magneticactivated cell sorting (MACS) (Miltenyi Biotec), allowing the separation of erythrocytes infected with hemozoin expressingparasites. Non-infected blood from the same donors was cultured in the same conditions and the media was changed every day. Infected RBCs were collected after 3 parasite life cycles. A MACS was performed when parasites were mainly late trophozoites and/or early schizonts. After MACS, parasitemia of infected RBCs was adjusted at $45 \%$ with non-infected RBCs providing from the same blood donor. Non-infected RBCs were also collected for ghost's production.

For proteome and phosphoproteome analysis, fresh blood from $3 \mathrm{HbAA}$ and $3 \mathrm{HbAS}$ donors was used. Ghosts and parasite proteins were prepared on three occasions, with one HbAA and one $\mathrm{HbAS}$ sample each time $\left(\mathrm{HbAA}_{1}\right.$ and $\mathrm{HbAS}_{1}$ were used simultaneously, so as $\mathrm{HbAA}_{2}$ with $\mathrm{HbAS}_{2}$, and $\mathrm{HbAA}_{3}$ with $\mathrm{HbAS}_{3}$ ). As phosphorylation of proteins can change with time after blood collection (Azouzi et al., 2018), HbAA and HbAS blood were sampled the same day, washed, infected and collected at the same time. The same experimental procedure was performed for all coupled HbAA-HbAS samples.

\section{Determination of Plasmodium falciparum Growth by Flow Cytometry}

Growth assays were performed with cryoconserved erythrocytes (from $\mathrm{HbAA}_{1}, \mathrm{HbAA}_{2}, \mathrm{HbAS}_{1}$ and $\mathrm{HbAS}_{2}$ blood donors) that were thawed for this experiment. Parasitemia was determined by flow cytometry every $24 \mathrm{hrs}$. For each condition, $100 \mu \mathrm{l}$ of resuspended culture were sampled and fixed with phosphatebuffered saline (PBS)-1\% paraformaldehyde for 30 minutes at room temperature. Then, $10^{11}$ cells (in PBS) per well were distributed in a 96-well plate. RBCs were labeled with PBS Hoechst (BD Biosciences, Hoechst 34580) (HO) $(1 \mu \mathrm{g} / \mathrm{ml})$ and incubated 45 minutes at $37^{\circ} \mathrm{C}$ in the dark before acquisition and analysis by flow cytometry (FACS Canto II BD). Using FlowJo software, the geomean values of $\mathrm{HO}$ fluorescence were used to characterize the parasitemias.

For parasites growth in fresh blood for proteomics analysis, blood smears were also performed every $24 \mathrm{hrs}$ and observed by microscopy to follow $P$. falciparum growth and observe the parasite stages.

\section{Preparation of Erythrocyte Ghosts}

HbAA and HbAS erythrocyte ghosts (RBC membranes and cytoskeleton) were obtained by hypotonic lysis at $4^{\circ} \mathrm{C}$ of either infected or non-infected erythrocytes according to a protocol from Azouzi et al. (2015). The RBCs were first washed three times in PBS $1 \mathrm{X}$ and then incubated with 10 volumes of lysis buffer $\left(5 \mathrm{mM} \mathrm{Na}_{2} \mathrm{HPO}_{4}, 0.35 \mathrm{mM}\right.$ EDTA, pH 8.0 with proteases (Roche Diagnostics) and phosphatases inhibitors (SigmaAldrich)) for 5 minutes on ice. Solutions were afterwards centrifuged at $50,000 \mathrm{x} \mathrm{g}$ for 20 minutes at $4^{\circ} \mathrm{C}$. For the infected samples, the ghost layer was collected in a new tube to separate ghosts from parasite pellet. The reddish supernatant (containing hemoglobin) was removed, and the ghosts and parasites were washed in lysis buffer until the pellets became colorless. Protein extraction from erythrocyte membranes and parasites was performed by adding one volume of extraction buffer 3X (3\% NP40 (Sigma-Aldrich), 3\% SDS (Fluka), 90 mM Tris $\mathrm{pH} 8,3$ mM EDTA, pH 8 with proteases (Roche Diagnostics) and phosphatases inhibitors (Sigma-Aldrich)) to two volumes of each pellet. For parasite extracts, a supplementary sonication step was realized to solubilize the proteins. The protein content was measured by BCA (bi-cinchoninic acid) assay (Micro BCA ${ }^{\mathrm{TM}}$ Protein Assay Kit, ThermoFischer Scientific). The preparations were finally stored at $-80^{\circ} \mathrm{C}$ until analysis.

\section{Sample Preparation and Mass Spectrometry}

Proteins, from erythrocyte membrane or from parasite extracts, $(100 \mu \mathrm{g})$ were first solubilized in $2 \%$ SDS pH 7.5 and heated at $95^{\circ} \mathrm{C}$ for 5 minutes. Samples were then reduced with $0.1 \mathrm{M}$ dithiothreitol (Sigma-Aldrich) at $60^{\circ} \mathrm{C}$ for 1 hour. Mass spectrometry (MS) sample preparation was performed using a filter aided sample preparation (FASP) method according to Lipecka et al. (2016). We set aside $10 \%$ of the peptides for total ghost proteome analysis, while the remaining sample was used for phosphopeptide enrichment, according to the schematic workflow (Figure 1).

\section{Phosphopeptide Enrichment by Titanium Dioxide $\left(\mathrm{TiO}_{2}\right)$}

Phosphopeptide enrichment was carried out using a Titansphere $\mathrm{TiO}_{2}$ Spin tips $(3 \mathrm{mg} / 200 \mu \mathrm{L}$, Titansphere PHOS$\mathrm{TiO}$ (GL Sciences Inc) on the digested proteins for each biological replicate according to manufacturer's instructions. Samples were applied to the $\mathrm{TiO}_{2}$ Spin tips three times in total in order to increase the adsorption of the phosphopeptides to the $\mathrm{TiO}_{2}$. Phosphopeptides were eluted by the sequential 


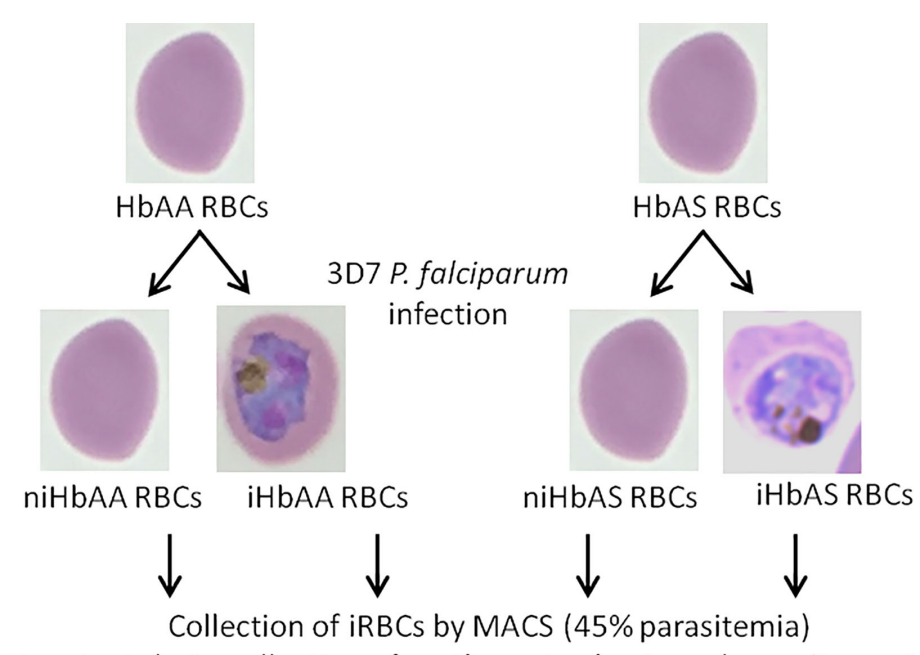

Hypotonic lysis: collection of erythrocyte ghosts and parasite proteins

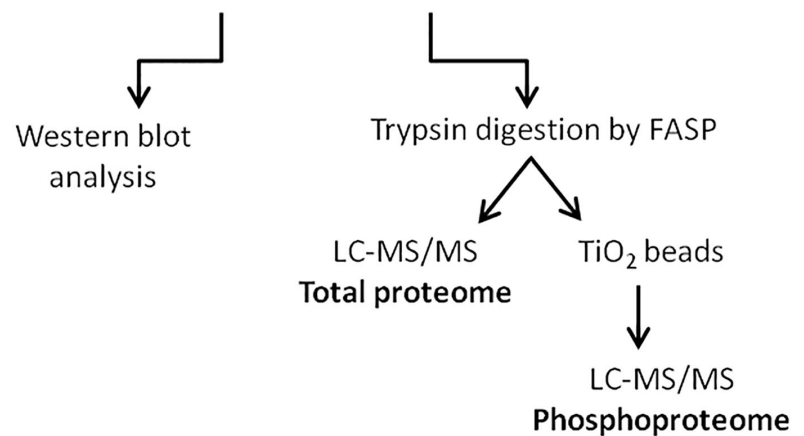

FIGURE 1 | Schematic workflow of infected and non-infected HbAA and HbAS erythrocytes proteome and phosphoproteome experimental procedures - HbAA and $\mathrm{HbAS}$ erythrocytes were collected and infected in vitro with the 3D7 P. falciparum strain. Mature trophozoite/schizont-infected RBCs were collected by MACS (45\% parasitemia) and lysed to produce ghosts and collect parasites. Membrane erythrocyte lysates were analyzed by western blot. For mass spectrometry, after trypsin digestion of proteins, phosphopeptides were enriched on $\mathrm{TiO}_{2}$ columns and analyzed by LC-MS/MS. Total proteomes of erythrocyte and parasite proteins were also generated. i, infected; ni, non-infected.

addition of $50 \mu \mathrm{L}$ of $5 \% \mathrm{NH}_{4} \mathrm{OH}$ and $50 \mu \mathrm{L}$ of $5 \%$ pyrrolidine. Phosphopeptides were washed and eluted with $70 \mu \mathrm{L}$ of $0.1 \%$ trifluoroacetic acid (TFA), 80\% acetonitrile high-performance liquid chromatography (HPLC)-grade (1,000 x g for 3 minutes) and vacuum dried.

\section{NanoLC-MS/MS Protein Identification and Quantification}

Samples were resuspended in $10 \mu \mathrm{L}$ of $0.1 \%$ TFA in HPLC-grade water. For each run, $1 \mu \mathrm{L}$ was injected in a nanoRSLC-Q Exactive PLUS (RSLC Ultimate 3000) (Thermo Scientific). Phosphopeptides were loaded onto a $\mu$-precolumn (Acclaim PepMap 100 C18, cartridge, $300 \mu \mathrm{m}$ i.d. $\times 5 \mathrm{~mm}, 5 \mu \mathrm{m}$ ) (Thermo Scientific), and were separated on a $50 \mathrm{~cm}$ reversed-phase liquid chromatographic column (0.075 mm ID, Acclaim PepMap 100, C18, $2 \mu \mathrm{m}$ ) (Thermo Scientific). Phosphopeptides were analyzed using mass spectrometry parameters according to Meijer et al. (2017).

The MS files were processed with the MaxQuant software version 1.5.8.3 and searched with Andromeda search engine against a merged database of human from Swissprot 2011-10-19 and P. falciparum from Swissprot and PlasmoDB 8.1 (26047 entries in total). MS files from total ghosts (proteome) and from $\mathrm{TiO}_{2}$ enriched peptides (phosphoproteome) were searched using two parameters groups. To search parent mass and fragment ions, we set a mass deviation of $4.5 \mathrm{ppm}$ and $20 \mathrm{ppm}$ respectively. Strict specificity for trypsin/P cleavage was required, allowing up to two missed cleavage sites. Carbamidomethylation (Cysteine) was set as fixed modification, whereas oxidation (Methionine) and N-term acetylation were set as variable modifications. For the analysis of MS files issued of $\mathrm{TiO}_{2}$ enrichment, the variable modification of phosphorylation on $\mathrm{S}, \mathrm{T}$ and $\mathrm{Y}$ was also added. The false discovery rates (FDRs) at the protein and peptide level were set to $1 \%$. Scores were calculated in MaxQuant as described previously (Cox and Mann, 2008). Match between runs was allowed. The reverse hits were removed from MaxQuant output. Proteins were quantified according to the MaxQuant label-free algorithm using label-free quantification (LFQ) intensities (Cox and Mann, 2008; Cox et al., 2014) and phosphopeptides according to intensity; protein and peptide quantification were obtained using at least one peptide per protein. 
Statistical and bioinformatic analysis, including heatmaps, profile plots and clustering, were performed with Perseus software (version 1.6.0.7) freely available at www.perseusframework.org (Tyanova et al., 2016). For statistical comparison of the ghost proteome, we set four groups niHbAA, iHbAA, niHbAS, iHbAS. Each group contained three biological replicates (different donors). Each sample was also run in technical triplicates.

For total ghost proteome analysis, we analyzed the proteingroups.txt file. Protein LFQ intensities were transformed in $\log (2)$. Proteins were separated into Plasmodium and human to select the RBC derived proteins. We filtered the data to keep only proteins with at least three valid values in at least one group. Data were imputed to fill missing data points by creating a Gaussian distribution of random numbers with a standard deviation of $33 \%$ relative to the standard deviation of the measured values and 1.8 standard deviation downshift of the mean to simulate the distribution of low signal values. We performed an ANOVA test, $p$-value $<0.01$, $\mathrm{S} 0=0.1$.

For phosphopeptide analysis, we analyzed the Phospho (STY).txt file. Phosphopeptide intensities were transformed in $\log (2)$, site table was expanded to analyze all phosphosites separately. Phosphosites were separated into Plasmodium and human to select the RBC derived phosphoproteins. We filtered the data to keep only phosphosites with at least three valid values in at least one group. Only phosphosites with at least 0.75 of localization probability were retained. Phosphosite intensities were normalized by subtracting the median and adding a constant (25). Data were imputed to fill missing data as described above. We performed an ANOVA to compare the four groups, $p$-value $<0.05, \mathrm{~S} 0=0.1$. To evaluate the influence of the genotype on the infection, and if it induces variations, we also performed a two-way ANOVA test, separating the infection and the genotype factors, interaction $p$-value $<0.05$. Data were imputed to fill missing values points by creating a Gaussian distribution of random numbers with a standard deviation of $33 \%$ relative to the standard deviation of the measured values and 3 standard deviation downshift of the mean to simulate the distribution of very low signal values. We performed a $t$-test to compare the parasite phosphoproteome after infection in $\mathrm{HbAA}$ vs $\mathrm{HbAS}, \mathrm{FDR}<0.05$, S0 = 0.5.

Hierarchical clustering of phosphosites/proteins that survived the tests was performed in Perseus on log-transformed LFQ intensities after $\mathrm{z}$-score normalization of the data, using Euclidean distances.

The mass spectrometry proteomics data have been deposited to the ProteomeXchange Consortium via the PRIDE (PerezRiverol et al., 2019) partner repository with the dataset identifier PXD023280.

\section{SDS-PAGE and Western Blot}

To complete our proteome and phosphoproteome analysis, all erythrocyte ghost samples were also analyzed by anti-Band 3 and anti-pY Band 3 western blots (Figure 1).

Ghost lysates $(20 \mu \mathrm{g})$ were mixed with $5 \mathrm{X}$ loading buffer (1.25 mM sucrose, 20\% SDS, $250 \mathrm{mM}$ Tris- $\mathrm{HCl}, 25 \%$ $\beta$-mercaptoethanol, 1\% bromophenol blue, $\mathrm{pH} 6.8$ ) and heated at $70^{\circ} \mathrm{C}$ for 10 minutes. Proteins were separated by $4-12 \%$ gradient SDS-PAGE under reducing conditions and then transferred to nitrocellulose membrane (Trans-Blot ${ }^{\circledR}$ Turbo $^{\mathrm{TM}}$ RTA Mini Nitrocellulose Transfer Kit) (BioRad). Blots were blocked with tris buffered saline (TBS) - 5\% bovine serum albumin (BSA) (Roche Diagnostics), then probed with primary antibodies (mouse anti-Band 3 monoclonal IgG 1,20000 (SigmaAldrich), rabbit anti-pY $\mathrm{P}^{359}$ Band 3 polyclonal IgG 1,10000 (Abcam), rabbit anti-pY ${ }^{21}$ Band 3 polyclonal IgG 1,10000 (Abcam) or rabbit anti-p55, 1,50000, used as a loading control, in TBS- 5\% BSA) and finally with the appropriate peroxidaseconjugated secondary antibody (goat anti-rabbit polyclonal IgG 1,5000 (Jackson ImmunoResearch (Interchim)), or goat antimouse polyclonal IgG 1,5000 (Jackson ImmunoResearch (Interchim)) applied in TBS - 5\% BSA. Detection was performed using the electrochemiluminescence (ECL) Plus Western blotting detection system (Amersham Biosciences).

Anti-pY ${ }^{21}$ Band 3/- $\mathrm{pY}^{359}$ Band 3 and p55 western blots were performed on the same membrane. These membranes were then stripped and incubated with mouse anti-Band 3 antibody. After ensuring that the loading was similar for each condition with p55 western blots, Image Lab 6.0.1 software was used to measure the intensity of $\mathrm{pY}^{21}$ Band 3, $\mathrm{pY}^{359}$ Band 3 and Band 3 band signals. Subsequently, as inter-individual variations cannot be excluded, $\mathrm{pY}^{21}$ Band 3 or $\mathrm{pY}^{359}$ Band 3 intensities were normalized according to the corresponding Band 3 intensity for all donors.

\section{RESULTS}

\section{Characterization of Hemoglobin Genotype of Blood Donors}

For all the experiments, we obtained blood from three abnormal $\mathrm{Hb}$ carriers $\left(\mathrm{HbAS}_{1}, \mathrm{HbAS}_{2}\right.$, and $\left.\mathrm{HbAS}_{3}\right)$, and from three normal $\mathrm{Hb}$ carriers $\left(\mathrm{HbAA}_{1}, \mathrm{HbAA}_{2}, \mathrm{HbAA}_{3}\right)$. We verified their $\mathrm{Hb}$ genotype by PCR-RFLP and compared their profiles to control DNA. We confirmed that all the abnormal $\mathrm{Hb}$ carriers were $\mathrm{HbAS}$ and all the normal $\mathrm{Hb}$ ones were HbAA (Supplementary Figure 1). All information concerning the donors and their genotypes is summarized in Supplementary Table 1.

\section{Parasite Growth Is Slower in HbS Heterozygous Carriage Than in HbAA Red Blood Cells}

Before collecting infected erythrocytes in order to prepare ghosts and harvest parasites, we compared $P$. falciparum growth in HbAA versus HbAS RBCs. We assessed parasite replication rates by flow cytometry in RBCs provided from two HbAA and two HbAS donors. We observed a significant slower replication rate for P. falciparum grown in HbAS RBCs (Figure 2). Although parasite growth seems very low for parasites inside HbAS erythrocyte, parasites grew, and progressed from schizonts to ring and from ring to schizonts in HbAS erythrocytes. Microscopic observation revealed no difference in the proportions of different parasites developmental stages during the two first cycles of replication up to $96 \mathrm{~h}$ post-infection. From 
the third cycle onwards, however, we observed a slight retardation of parasite growth in HbAS erythrocytes (Figure 2B).

\section{Erythrocyte Membrane Proteome as a Function of Plasmodium falciparum Infection and/or Abnormal Hemoglobin S Carriage}

Therefore, to investigate the proteome and phosphoproteome of Plasmodium falciparum-infected HbAA and HbAS erythrocytes, parasite development in the two types of RBCs was allowed to proceed for three cycles, and was assessed via sequential blood smears, to allow for adequate adaptation to the host cells. Infected RBCs were collected at the same parasite stage after $140 \pm 2 \mathrm{~h}$ post-infection (Figure 1). We ensured that parasites were at the same stages (late trophozoites and early schizonts) in HbAA and HbAS RBCs, with blood smears made just prior to MACS (Figure 2B).
The total ghost proteome analyses led to identification of 1438 proteins across all samples, of which 910 were human (65\%) (Supplementary Table 2) and 528 parasite proteins (35\%). Most proteins identified were part of the erythrocyte cytoskeleton or transporters, confirming the enrichment in erythrocyte ghosts.

We observed significant differences in the quantity of 35 erythrocyte proteins according to infection and/or HbS carriage (Supplementary Table 2, in green) ( $p$-value $<0.05$ ) after an ANOVA test. Performing hierarchical biclustering, we identified 4 main clusters of proteins according to their intensity variations (Figure 3). Some proteins were of particular interest because their quantity varied according to both $P$. falciparum infection and $\mathrm{Hb}$ genotype. Compared to infected RBC and heterozygous HbS carriage, i) the protein lin-7 homolog A/C (black arrow) was detected less frequently in

A
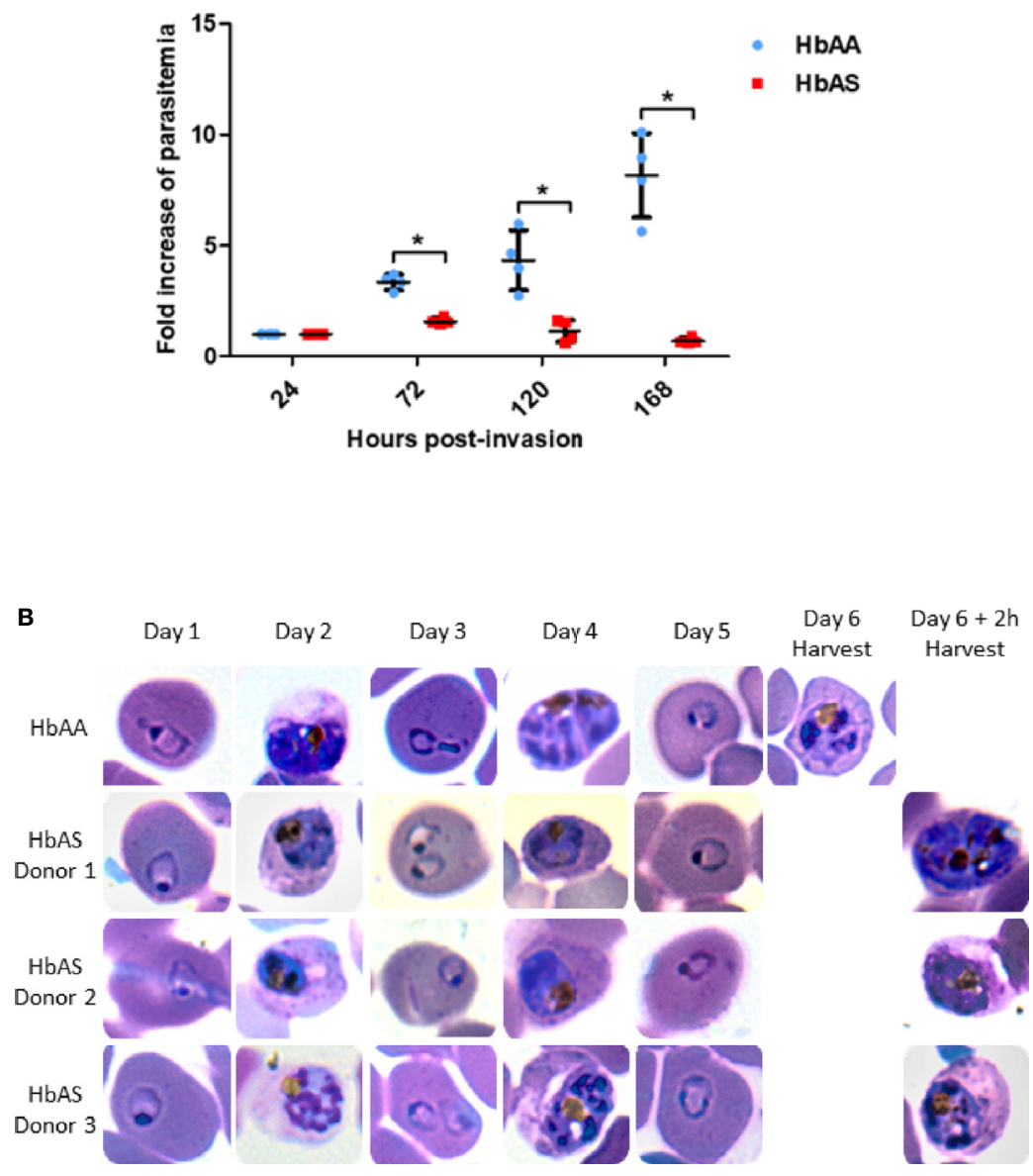

FIGURE 2 | Parasite replication in HbAA and HbAS RBCs assessed by flow cytometry (A) and by blood smears (B). Invasion of 2 HbAA (HbAA1 and HbAA2) and 2 $\mathrm{HbAS}$ (HbAS1 and HbAS2) blood samples from the cryobank of the the French National Immunohematology Reference Laboratory (CNRGS), was realized at $t=$ Oh. Parasitemia was assessed every 24h. To visualize the fold increase of parasitemia, all parasitemia values were divided by the initial parasitemia measured $24 \mathrm{~h}$ postinfection. Technical duplicates were performed for each donor, and replicate values for each point were loaded on the graph. Unpaired Mann-Whitney t-test ( $\mathrm{p}$-value<0.05) was used to compare values from HbAA and HbAS groups at 24h, 72h, 120h and 168 h., asterisks (*) indicate significantly different values (A). Parasite development in one $\mathrm{HbAA}(\mathrm{HbAA} 1$ as a reference) and $3 \mathrm{HbAS}(\mathrm{HbAS} 1, \mathrm{HbAS} 2$ and HbAS3) blood donors erythrocytes. Invasion of fresh blood samples was realized at $\mathrm{t}=\mathrm{Oh}$. Blood smears were performed every $24 \mathrm{~h}$ for six days. At day 6 , blood smears were realized right before MACS collection (B). 
infected HbAA ghosts and ii) Heme-binding protein 1, and UPF0687 protein C20orf27 (Cluster 3), were detected more frequently in HbAA infected samples.

\section{Erythrocyte Membrane Phosphoproteome as a Function of Plasmodium falciparum Infection and/or Abnormal Hemoglobin S Carriage}

Phosphoproteomic analysis led to the quantification of 499 phosphosites from erythrocytic proteins, of which 413 serines (Ser or S), 81 threonines (Thr or T) and only 4 tyrosines (Tyr or Y). Performing an ANOVA test, we observed significant differences in the phosphorylation intensity of several erythrocyte proteins in association with $P$. falciparum infection and/or abnormal HbS carriage ( $p$-value $<0.05$ ) (Supplementary Table 3). We identified 58 differentially phosphorylated sites corresponding to 33 distinct proteins (Figure 4). Most of the differential phosphosites were serine residues (44 serines, 13 threonines and 1 tyrosine). Among these phosphosites, 50 had already been described; the 8 remaining were identified in the present work for the first time, corresponding to 6 different new phosphoproteins. For each phosphosite, we ensured that its phosphorylation variation was not due to a different quantity of the corresponding protein, according to the global proteome analysis by LC-MS/MS of all samples (Supplementary Table 2).
Hierarchical clustering identified 5 residue phosphorylation modulation profiles (Figure 4). Cluster 1 is composed of 11 phosphosites over-phosphorylated in infected erythrocytes, including 5 sites that have already been described as "infection specific" in a meta-analysis of phosphoproteomic studies of P. falciparum iRBCs (Bouyer et al., 2016) $\left(\mathrm{S}^{726}\right.$ and $\mathrm{T}^{724}$ of $\alpha$ adducin, $S^{1301}$ of $\beta$-spectrin, $T^{238}$ of GLUT1 and $S^{849}$ of protein 4.1 ), validating our analytical approach. Cluster 4 included sites presenting decreased phosphorylation intensities due to the infection of RBCs ( $\mathrm{Y}^{359}$ of Band 3, $\mathrm{S}^{1381}$ of Tensin-1, $\mathrm{S}^{365}$ and $S^{366}$ of Serine/threonine-protein kinase MARK2). First, these results confirmed previous data by detecting the same phosphorylation sites. Second, these results complete previous data by quantifying the phosphorylation intensities according to $\mathrm{Hb}$ genotypes and infection status. The decrease in phosphorylation intensities was not detected in previous studies that analyzed in some cases only infected RBCs. This analysis also identified two clusters containing phosphosites for which the phosphorylation state depended on $\mathrm{Hb}$ status, cluster 3 and cluster 5. Pattern 2 and two proteins (black arrows) were of particular interest because they were proteins for which the phosphorylation state was strongly modified depending on the combination of both infection and abnormal $\mathrm{Hb}$ carriage. The phosphorylation intensity of $S^{31}$ of Serine/threonine protein kinase STK11 was stronger in non-infected HbAA RBCs. Cluster

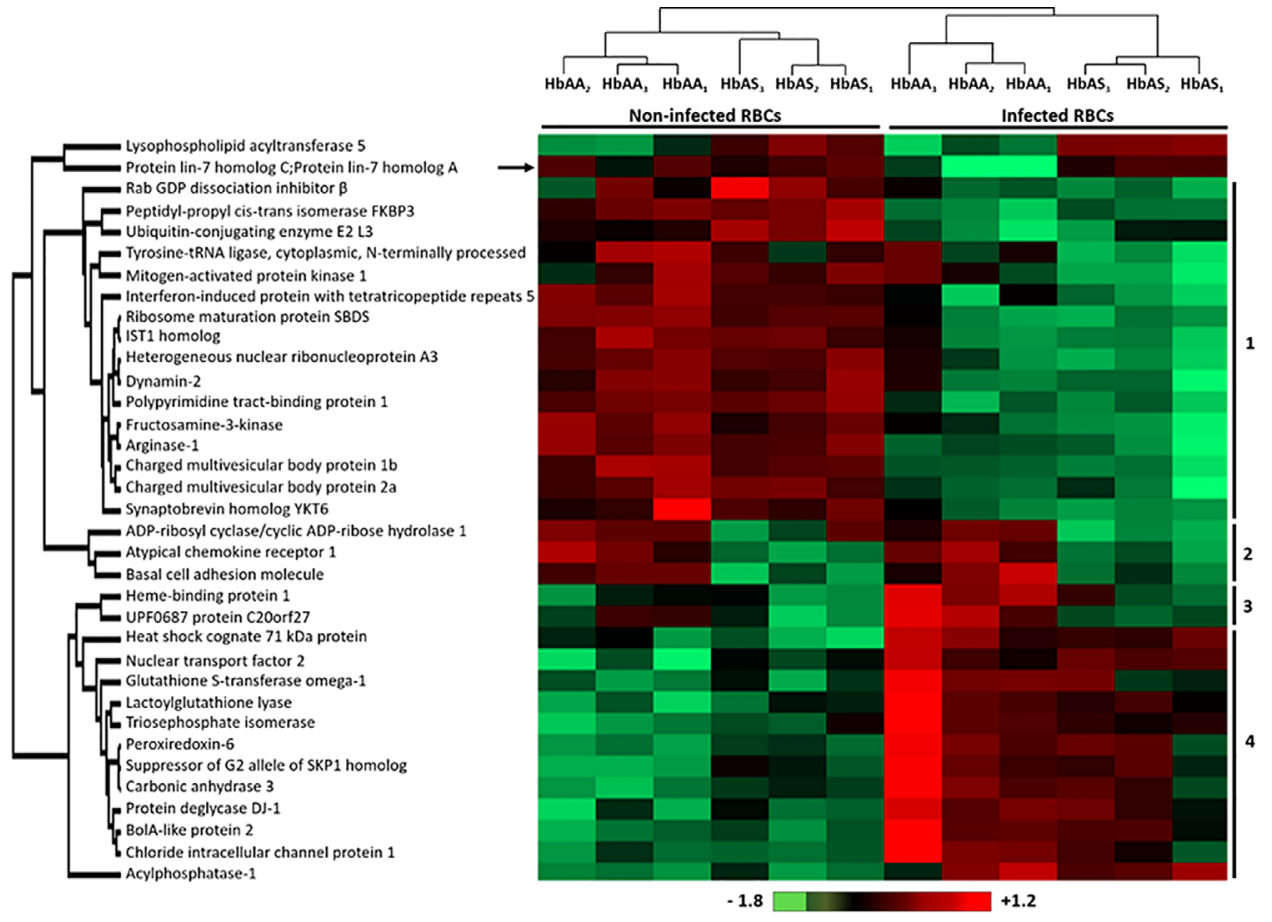

FIGURE 3 | Differentially detected human erythrocyte proteins as a function of $P$. falciparum infection and/or HbAS genotype. Six HbAA (non-infected and infected $\mathrm{HbAA}_{1}, \mathrm{HbAA}_{2}$, and $\mathrm{HbAA}_{3}$ ) and six $\mathrm{HbAS}$ (non-infected and infected $\mathrm{HbAS}_{1}, \mathrm{HbAS}_{2}$, and $\mathrm{HbAS}_{3}$ ) erythrocyte ghost samples were analyzed by hierarchical clustering based on the detected quantity of RBC proteins (ANOVA test, $p$-value $<0.05$ ). Samples are displayed horizontally (columns) and proteins are shown vertically (rows). The more the protein is represented in light red, the more it is detected in the corresponding sample, and the more it is colored in light green, the less it is detected. The color bar represents $\log _{2} Z$ score fold-change. Proteins are clustered according to their quantity profile, represented by dendograms. Black arrow: protein profile that cannot be associated with a cluster. 


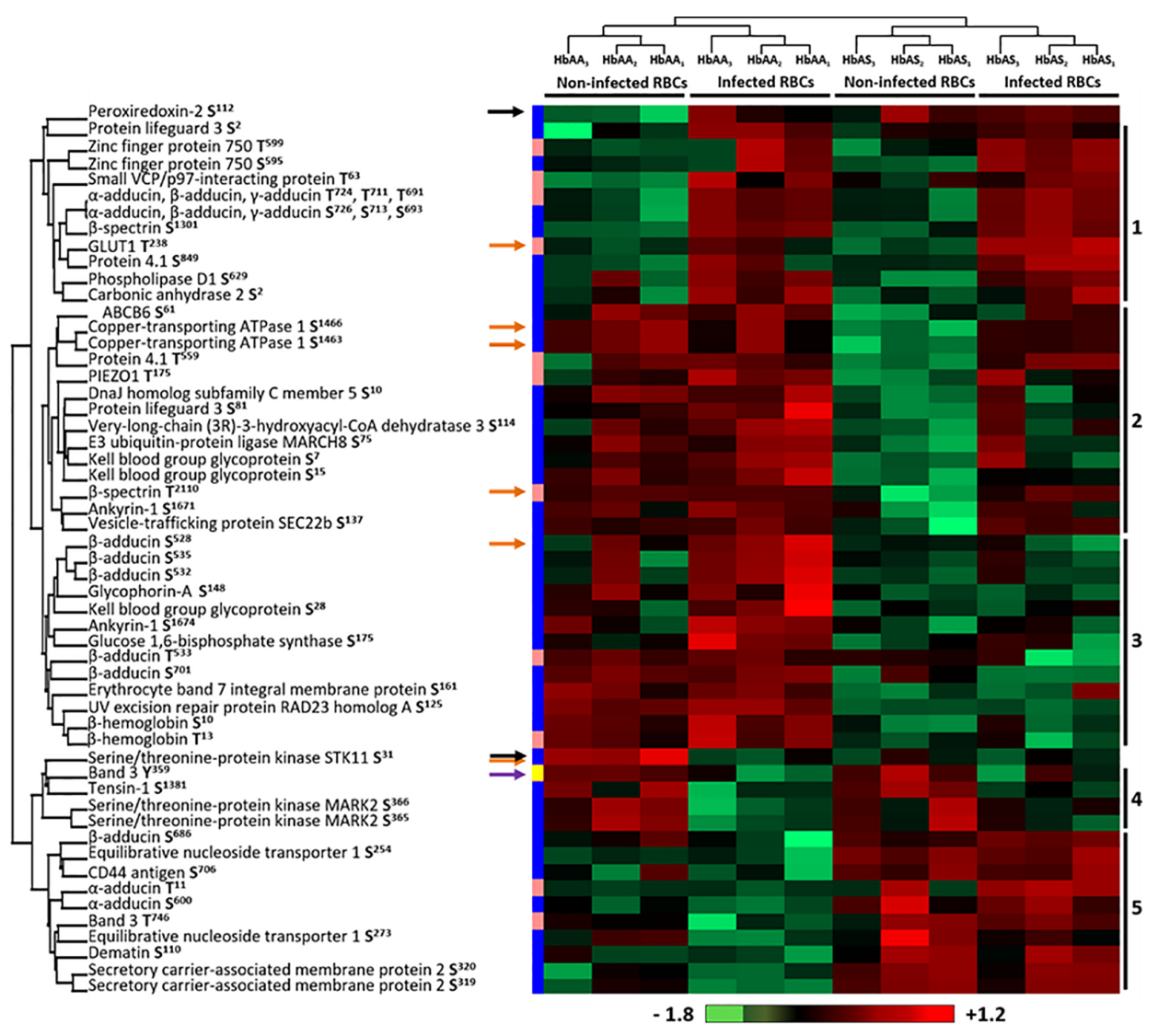

FIGURE 4 | Differentially phosphorylated sites of human erythrocyte proteins as a function of $P$. falciparum infection and/or HbAS genotype. Six HbAA (non-infected and infected $\mathrm{HbAA}_{1}, \mathrm{HbAA}_{2}$, and $\mathrm{HbAA}_{3}$ ) and six $\mathrm{HbAS}$ (non-infected and infected $\mathrm{HbAS}_{1}, \mathrm{HbAS}_{2}$ and $\mathrm{HbAS}_{3}$ ) were analyzed by hierarchical clustering based on the phosphorylation rate of a specific site of RBC proteins (ANOVA test, $p$-value $<0.05$ ). Samples are displayed horizontally (columns) and proteins are shown vertically (rows). Sites are specified next to the protein name. The more the site is represented in light red, the more it is phosphorylated in the corresponding sample, and the more it is colored in light green, the less it is phosphorylated. The color bar represents $\log _{2} Z$ score fold-change. On the left, threonine ( $T$ ) residues are in pink, serines (S) in blue and tyrosine (Y) in yellow. Proteins are clustered according to their phosphorylation profile, represented by dendograms. Black arrows: protein profiles that cannot be associated with a cluster, orange arrows: phosphosites differentially phosphorylated according to both $P$. falciparum infection and abnormal heterozygous HbS carriage.

2 was composed of $S^{61}$ of ATP-binding cassette transporter subfamily B member $6, S^{1463}$ and $S^{1466}$ of Copper-transporting ATPase $1, \mathrm{~T}^{559}$ of protein $4.1, \mathrm{~T}^{175}$ of PIEZO1, $\mathrm{S}^{10}$ of DnaJ homolog subfamily $\mathrm{C}$ member $5, \mathrm{~S}^{81}$ of Protein lifeguard $3, \mathrm{~S}^{114}$ of Very-long-chain (3R)-3-hydroxyacyl-CoA dehydratase 3, $S^{75}$ of E3 ubiquitin-protein ligase MARCH8, $\mathrm{S}^{7}$ and $\mathrm{S}^{15}$ of Kell, $\mathrm{T}^{2110}$ of $\beta$-spectrin, $S^{1671}$ of Ankyrin-1 and $S^{137}$ of Vesicle-trafficking protein SEC22b. These sites displayed a lower intensity of phosphorylation specifically in non-infected HbAS RBCs. Finally, the phosphorylation intensity of $S^{112}$ of Peroxiredoxin2 increased in all HbAS samples and infected HbAA ghosts. This protein protects cells against oxidative stress and its function can be regulated by phosphorylation (Rhee and Kil, 2017). This result may be the consequence of the oxidative stress generated by both $P$. falciparum infection and HbS.

We then performed a two-ways ANOVA to visualize the phosphosites differentially phosphorylated according to both P. falciparum infection and abnormal heterozygous $\mathrm{HbS}$ carriage (Supplementary Table 3$)(p$-value $<0.05)$. Six phosphosites were identified, corresponding to 5 different proteins (orange arrows).

\section{Plasmodium falciparum Infection Modulates Band 3 Tyrosine- Phosphorylation}

$\mathrm{TiO}_{2}$-based enrichment has similar affinity for the serine, threonine and tyrosine, but the proportion of phosphosites is correlated with the frequency of these phosphosites in the cell. As tyrosine-phosphorylation is less represented, it would require additional steps to collect tyrosine-phosphopeptides or the use of alternative approaches.

For this reason, the erythrocyte ghosts were also investigated by anti-phospho-tyrosine western blot (Figure 1). Band 3 protein is the major known target of erythrocyte tyrosine kinases (Ferru et al., 2011), and the enhancement of its tyrosine-phosphorylation due to oxidative stress has been 
described in previous reports (Pantaleo et al., 2010b; Ferru et al., 2011). Band 3 is known to be phosphorylated upon oxidative stress on several tyrosine residues including $\mathrm{Y}^{21}$ and $\mathrm{Y}^{359}$ by Syk and Lyn kinases, respectively. We confirmed the modulation of Band $3 \mathrm{Y}^{359}$ phosphorylation in our mass spectrometry analysis (purple arrow in Figure 4). Thus, after ensuring that the same amount of protein was loaded for each sample using an anti-p55 western blot, we used specific anti-pY $\mathrm{Y}^{21}$ and anti-pY ${ }^{359}$ Band 3 antibodies (complete Western blots are provided in Supplementary Figures 2 and 3). Band $3 \mathrm{Y}^{21}$ phosphorylation intensity increased with $P$. falciparum infection in both $\mathrm{HbAA}$ and HbAS erythrocytes (Figures 5A, C). We observed that Band $3 \mathrm{Y}^{359}$ phosphorylation intensity decreased with infection in both HbAA and HbAS RBCs (Figures 5B, D). This result confirms the profile observed for the same phosphosite in mass spectrometry (Figure 4). Furthermore, the decreased phosphorylation intensity of Band $3 \mathrm{Y}^{359}$ is significantly less marked in HbAS than in HbAA RBCs.

\section{Parasite Phosphoproteome as a Function of Abnormal Hemoglobin S Carriage}

Within the proteome and the phosphoproteome analysis, we also focused on the parasite proteins and we analyzed them according to $\mathrm{Hb}$ genotype of the erythrocyte in which $P$. falciparum grew (Figure 1). Proteome analysis revealed no significant difference in the protein amounts, with profiles showing individual variability.
Phosphoproteome analysis identified 27 phosphosites that were differentially phosphorylated according to $\mathrm{Hb}$ genotype, corresponding to 14 different phosphoproteins (Student $t$-test, $p$ value $<0.05$ ) (Supplementary Table 4). Performing hierarchical clustering, we could identify two patterns of phosphorylation profiles (Figure 6). Cluster 1 included phosphorylation sites in 8 proteins such as ring-infected erythrocyte surface antigen (RESA), Antigen 332 - DBL like protein, mature parasite-infected erythrocyte surface antigen (MESA), and unknown proteins with the following PlasmoDB identifiers, MAL13P1.380 (PF3D7_1343800), PFI0345w (PF3D7_0907200), PFL0555c (PF3D7_1211200) for which phosphorylation intensities were greater when parasites were cultured in HbAS RBCs than in HbAA RBCs. Cluster 2 was composed of phosphosites from 8 proteins, including Rhomboid protease 1 (ROM1), PFE1485w (PF3D7_052980), PF07_0016 (PF3D7_0704300), PFL1930w (PF3D7_1239800), PF11_0233 (PF3D7_1122500), MAL8P1.29 (PF3D7_0825000), PF14_0343 (PF3D7_1436200) and PFF0535c (PF3D7_0610900). All the phosphosites of cluster 2 were serines and showed higher phosphorylation intensities in parasites grown in $\mathrm{HbAA}$ compare to $\mathrm{HbAS}$ erythrocytes.

\section{DISCUSSION}

This project aimed to measure the impact of $\mathrm{HbS}$ on proteomic and phosphoproteomic regulation of $P$. falciparum-infected
A

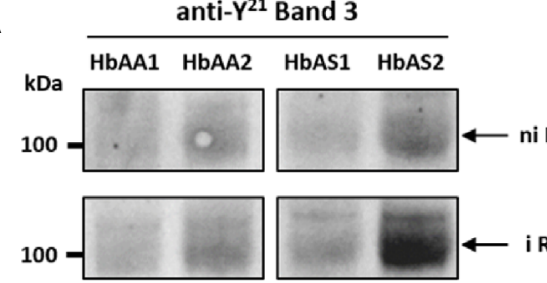

C

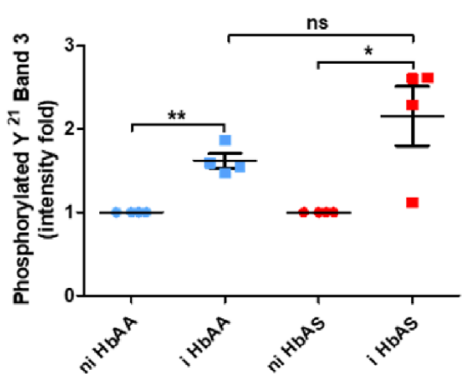

B

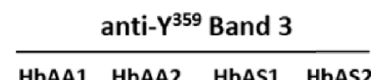

HbAA1 HbAA2 HbAS1 HbAS2
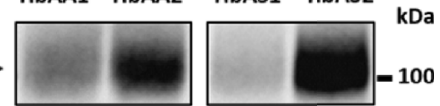

$\mathrm{RBC} \rightarrow$

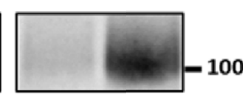

D

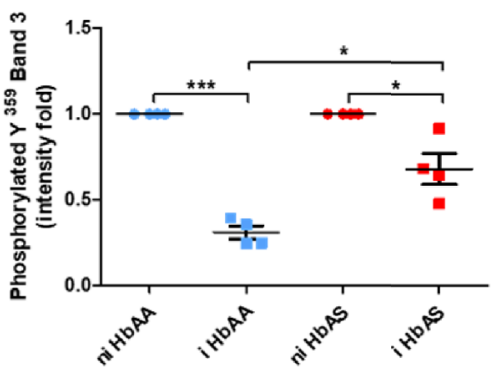

FIGURE 5 | Differences of Band $3 Y^{21}$ (A, C) and $Y^{359}$ (B, D) phosphorylation according to $P$. falciparum infection and abnormal hemoglobin S carriage. 4-12\% gradient gels were loaded with $20 \mu \mathrm{mg} / \mathrm{lane}$ of ghost protein extracts from $2 \mathrm{HbAA}$ (HbAA1 and HbAA2) and 2 HbAS (HbAS1 and HbAS2) donors. After separation of erythrocyte ghost lysate proteins by SDS-PAGE and transfer on nitrocellulose, tyrosine (Y)-phosphorylation was analyzed using anti-phosphoY21 (A) and antiphosphoY359 (B) Band 3 antibodies. Tyrosine phosphorylation intensities were measured with Image Lab software, and these intensities were normalized to Band 3 quantity detected on the same membrane by western blot. For each sample, the phosphorylation intensity value of infected condition was reported to the noninfected condition intensity value (C, D). Independent western blots were realized twice, and technical replicate values for each point were loaded on the graph. Phosphorylation fold intensities for HbAA and HbAS samples were represented in blue and red respectively, with non-infected (circles) and infected (square) ghosts. Paired t-test ( ${ }^{*} \mathrm{p}$-value $<0.05 ;{ }^{* *} \mathrm{p}$-value $<0.01$, and ${ }^{* \star *} \mathrm{p}$-value $<0.001$ ) were performed to compare intensities from the same genotype group (HbAA or HbAS) donors. Unpaired Mann-Whitney t-test ( ${ }^{\star} \mathrm{p}$-value $<0.05$; ${ }^{* *} \mathrm{p}$-value $<0.01$, and ${ }^{* \star *} \mathrm{p}$-value $<0.001$ ) was used to compare intensities from infected $\mathrm{HbAA}$ and infected $\mathrm{HbAS}$ donors. i, infected; ni, non-infected; ns, not significant. 


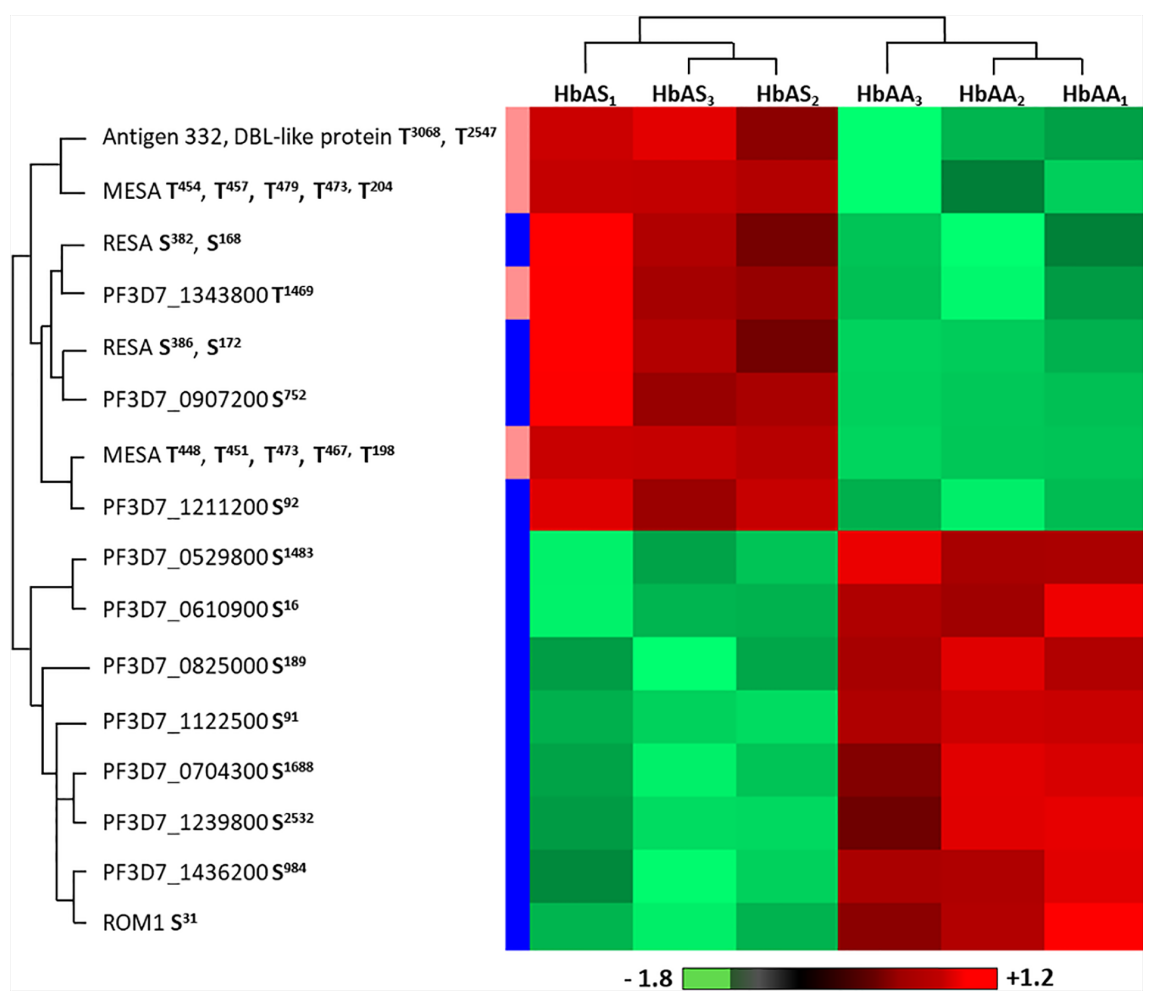

FIGURE 6 | Differentially phosphorylated sites of parasite proteins according to hemoglobin genotype. Parasites from three $\mathrm{HbAA}_{\mathrm{b}}$ (infected $\mathrm{HbAA}_{1}$, $\mathrm{HbAA}_{2}$, and $\mathrm{HbAA}_{3}$ ) and three $\mathrm{HbAS}$ (infected $\mathrm{HbAS}_{1}, \mathrm{HbAS}_{2}$, and $\mathrm{HbAS}_{3}$ ) extracts were analyzed by hierarchical clustering based on the phosphorylation's rate of a specific site of RBC proteins (Student's t-test, $p$-value $<0.05$ ). Samples are displayed horizontally (columns) and proteins are shown vertically (rows). Phosphosites are specified next to the protein name. The more the site is represented in dark red, the more it is phosphorylated in the corresponding sample, and the more it is colored in light green, the less it is phosphorylated. The color bar represents $\log _{2} Z$ score fold-change. On the left, threonine (T) residues are in pink and serines (S) in blue. Proteins are clustered according to their phosphorylation profile, represented by dendograms.

erythrocyte membrane proteins. We considered the impact of oxidative stress generated by both $\mathrm{HbS}$ heterozygous carriage and $P$. falciparum infection, because it could disturb the kinase/phosphatase equilibrium. Previous studies have investigated the phosphoproteome of HbSS and normal RBCs (George et al., 2010), or of HbAA erythrocytes after $P$. falciparum infection (Bouyer et al., 2016). To our knowledge, however, the phosphoproteome of HbAS RBCs has never been studied before. This study is also the first experimental, comparative and quantitative analysis of parasite and human protein phosphorylation of $\mathrm{HbAA}$ - and $\mathrm{HbAS}$-infected erythrocyte membranes.

Other erythrocyte genetic abnormalities, such as $\alpha$ thalassemia and glucose-6-phosphate dehydrogenase (G6PD) deficiency, can also confer protection against malaria (Taylor et al., 2013; Kakande et al., 2020) and coexist in populations affected by HbS in malaria endemic areas. Thus, the co-carriages of these other RBC disorders with $\mathrm{HbS}$ have been considered in this work (Supplementary Figures S4-S6). Investigation in the present study of cumulative erythrocyte disorders along with $\mathrm{HbS}$ led to the identification of G6PD deficiency carriages for the $\mathrm{HbAS}_{2}$ and $\mathrm{HbAS}_{3}$ donors. Also, $\mathrm{HbAS}_{2}$ and $\mathrm{HbAS}_{3}$ were heterozygous for $\alpha$-thalassemia. We cannot exclude that these additional mutations may have an effect on Plasmodium falciparum infection. It is of note that the consequences of the interactions between sickle cell trait and G6PD deficiency with respect to malaria resistance conferred to carriers is still controversial. Further studies need to be performed to analyze and identify any epistasis between these two genetic disorders (Esoh and Wonkam, 2021). In our proteomics works, statistical analyses were performed in order to conserve only proteins that were differentially phosphorylated or abundant in all the HbAS samples compared to all HbAA samples. Moreover, our cohort, albeit small, reflects the reality, as the co-carriage of $\mathrm{HbS}$ with G6PD deficiency and alpha-thalassemia are frequently found in malaria endemic areas (Chauvet et al., 2019; Okafor et al., 2019). It is also important to note here that one of our donors, $\mathrm{HbAS}_{1}$, only has sickle cell trait. However, to decipher accurately the impact of each mutation and of each combination of mutations on parasite development, further studies with large cohorts including individual carriage of these different genetic disorders, and all possible combinations of co-carriage of genetic disorders, should be conducted. Our own published work highlighted the importance of considering multiple RBC genotypes in studies of parasite antigen presentation at the erythrocyte surface. 
P. falciparum growth was compared in HbAA and HbAS RBCs in our culture conditions. Indeed, parasite development in HbAS erythrocytes can be inhibited according to culture medium and atmospheric conditions, notably in hypoxia (Archer et al., 2018). We followed the course of parasite growth either by flow cytometry or blood smears over at least three cycles, in RBCs from HbAA and HbAS donors, and observed a lower replication rate for parasites grown in HbAS RBCs. These data could be seen as consistent with $\mathrm{HbAS}$-conferred resistance against $P$. falciparum malaria. Although it is better to work with fresh blood, previous studies demonstrated similar results with cryoconserved erythrocytes (Egan et al., 2018; Kariuki et al., 2020), so for convenience, cryoconserved RBCs can be used.

Concerning erythrocyte proteins, modifications of both quantity and phosphorylation were identified, as summarized in Figure 7. Proteomic analysis revealed a group of proteins for which the quantity varied according to both infection and HbAS genotype. The current literature on Protein Lin-7 homolog A/C in red cells

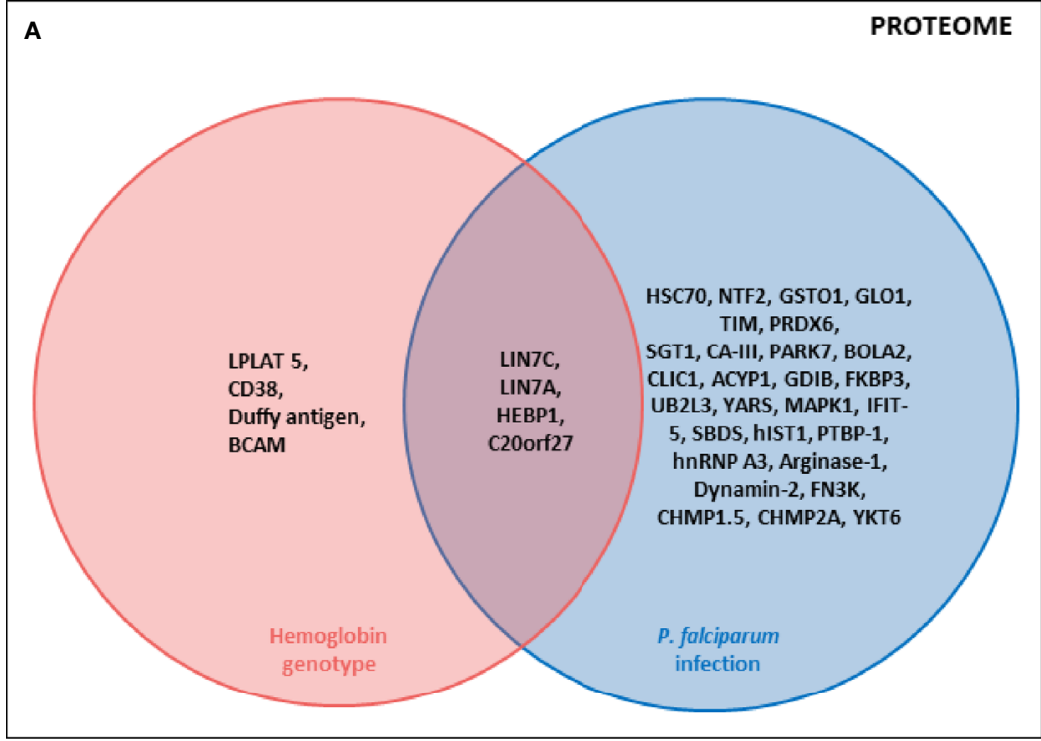

B

PHOSPHOPROTEOME

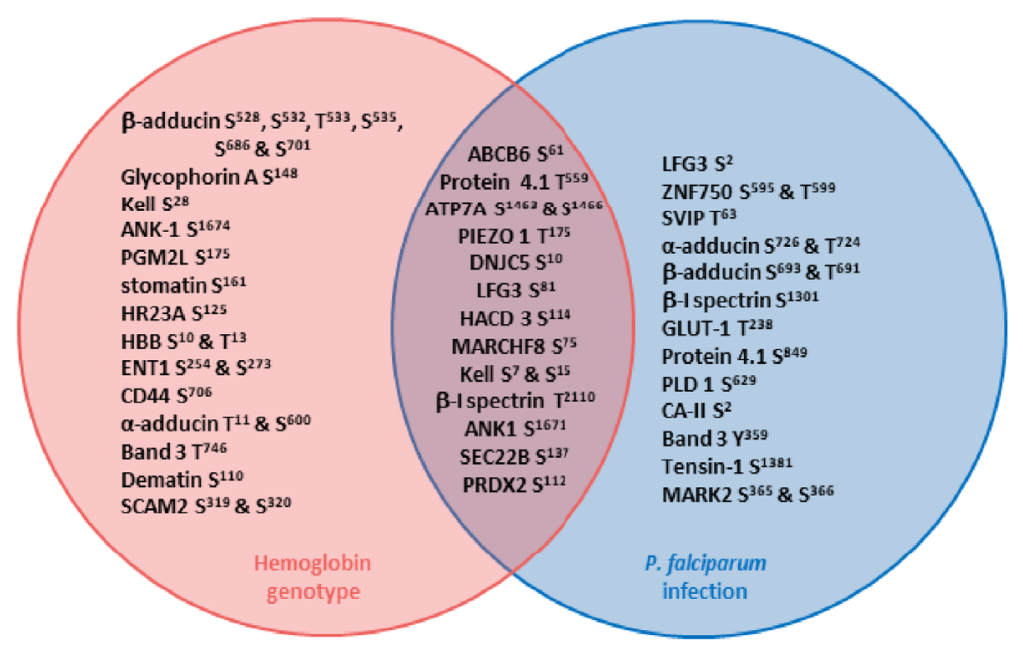

FIGURE 7 | Summary diagrams of proteome (A) and phosphoproteome (B) modulations of erythrocyte proteins according to $P$. falciparum infection and HbS carriage. Venn diagrams describing proteins whose quantity (A) or phosphorylation intensity (B) are varying according to hemoglobin genotype, $P$. falciparum infection or both parameters. Uniprot short names of proteins were represented, and phosphosites indicated. Erythrocyte proteins whose quantity (A) or phosphorylation intensity (B) was varying according to only hemoglobin genotype (ANOVA test) were presented in the pink circle. Erythrocyte proteins whose quantity (A) or phosphorylation intensity (B) was varying according to only $P$. falciparum infection (ANOVA test) were presented in the blue circle. Erythrocyte proteins whose quantity $(\mathbf{A})$ or phosphorylation intensity $\mathbf{( B )}$ was varying according to both hemoglobin genotype and $P$. falciparum infection (ANOVA test) were presented in the junction between the pink and the blue circle. 
does not allow us to explain the decrease in its quantity in iRBC HbAA. However, the HEBP1 protein was of particular interest. Indeed, this protein binds to free porphyrinogens and facilitates the elimination of elements potentially toxic for the cell (Jacob Blackmon et al., 2002). To our knowledge, no link between this protein and P. falciparum infection metabolism has ever been established. However, one can imagine that this protein could be necessary for the detoxification of the free heme generated during $P$. falciparum growth, because the quantity of this protein detected at the erythrocyte membrane increases with infection in $\mathrm{HbAA}$ RBCs. Heme detoxification is a key mechanism for parasite development, and is notably targeted in the development of drugs for malaria. However, the quantity of HEBP1 detected by mass spectrometry analysis does not increase in HbAS ghosts with $P$. falciparum infection. Therefore, it can be hypothesized that hemozoin formation and heme detoxification could be altered in HbAS RBCs.

Furthermore, the "Atypical chemokine receptor 1 » protein, also known as Duffy antigen, was detected at lower levels in the HbAS erythrocyte membrane. The Duffy antigen is known to be a receptor for the parasite Plasmodium vivax. Moreover, the Duffy null blood group confers protection against $P$. vivax malaria (Langhi and Bordin, 2006). To our knowledge, protection conferred by this blood group against $P$. falciparum malaria has never been described. A recent study reported a clinical case where a HbSS individual did not present any protection against $P$. vivax malaria (Moiz and Majeed, 2018). However, a more frequent association between $\mathrm{HbS}$ and Duffy null blood group has been observed, this combination being potentially selected in areas where $P$. falciparum and $P$. vivax malaria are both frequent (Gelpi and King, 1976), in particular in sub-Saharan Africa, a region from which the $3 \mathrm{HbAS}$ blood donors originate. But for now, these observations don't allow us to suggest any mechanistic hypothesis regarding the potential role of a lower amount of Duffy antigen in conferring resistance to $P$. falciparum $\mathrm{RBC}$ invasion in HbAS carriers.

In our phosphoproteome analysis, proteins from 4 main groups were identified : (i) proteins from the Ankyrin-R complex (ankyrin, Band 3, $\beta$ spectrin, stomatin, and glycophorin A); (ii) proteins from the junctional complex (protein 4.1, dematin, $\alpha, \beta$ and $\gamma$ adducins, CD44, Duffy and Kell); (iii) carriers and channels (GLUT1, ENT1, PIEZO1, Secretory carrier-associated membrane protein 2, ABCB6 and Band 3); and (iv) kinases (Serine/threonine-protein kinase MARK2, Serine/threonine-protein kinase STK11). These phosphorylation changes could have an impact on the function of the different proteins, and thus on the structure and stability of the membrane of iRBCs. Indeed, phosphorylation of $\beta$ spectrin by the casein kinase 1, associated with the membrane, leads to decreased mechanical stability of the membrane (Manno et al., 1995). Phosphorylation of dematin by the parasite kinase FIKK (Brandt and Bailey, 2013), or by a PKA, seems to disturb its function, interfering with its binding with actin and spectrin (Lalle et al., 2011). Finally, phosphorylation of protein 4.1 following infection (Chishti et al., 1994) inhibits its ability to promote the interaction between actin and spectrin, reducing membrane stability (Manno et al., 1995) and could participate in parasite-induced modifications of membrane properties.
These modifications could also modulate erythrocyte membrane permeability. During its intra-erythrocytic development, $P$. falciparum uses some of these transporters for its metabolism. In our work, we have shown that the protein ABCB6, a heme transporter, displayed lower phosphorylation intensity in non-infected HbAS RBCs, compared to infected HbAS, and infected or non-infected HbAA erythrocytes. However, a study recently observed that $\mathrm{ABCB} 6$-deficient $\mathrm{RBCs}$ were resistant to invasion by $P$. falciparum (Egan et al., 2018).

The two-way ANOVA test highlighted sites at which the phosphorylation intensity varied according to both infection and HbAS genotype. The lack of antibodies corresponding to those phosphosites did not allow us to validate the observed variations of phosphorylation intensities by western blot. All the identified modifications could thus be involved in regulation of $P$. falciparum development and in molecular interactions in the membrane protein complexes, such as the cytoadherence complex, which is associated with the cytoadherence of iRBCs and therefore with severe forms of malaria.

Concerning parasite proteins, although the proteome appeared unchanged according to our observations, the phosphorylation intensities of serines and threonines of some parasite proteins, such as RESA, MESA, Pf332 and ROM1, did vary according to the $\mathrm{Hb}$ genotype of the RBCs. RESA is a protein involved in parasite $\mathrm{RBC}$ invasion that is expressed from the ring stage, where it plays a major role in the reduction of membrane deformability. After invasion, RESA is phosphorylated and binds close to the site of auto-association of $\beta$ spectrin dimers. This binding stabilizes the spectrin tetramer, by preventing the dimer dissociation that is necessary for invasion, strengthening the RBC membrane and preventing other invasion events (Pei et al., 2007). MESA is a phosphoprotein associated with the erythrocyte skeleton that interacts with 4.1 protein, at a position involved in the formation of the ternary complex (between p55, GPC and 4.1). MESA competes with $\mathrm{p} 55$ for the binding of 4.1 protein, and could thus impact iRBC membrane skeleton stability (Waller et al., 2003). Binding of MESA with 4.1 protein is crucial for parasite survival in the RBC, and also for correct localization of MESA in the erythrocyte skeleton (Black et al., 2008). MESA also binds to the cytoskeletal protein ankyrin (Kilili et al., 2019). Moreover, Pf332, a MCs resident peripheral protein, is associated with the erythrocyte cytoskeleton, at the schizont stage, where it binds to actin (Waller et al., 2010). Pf332 plays a role in membrane rigidity reduction, for PfEMP1 trafficking and for iGRs adherence (Glenister et al., 2009). Indeed, RBCs infected by $P f 332$-deficient parasites are more rigid, express less PfEMP1 and display lower adherence to CD36. Finally, ROM1 plays a role in the parasitophorous vacuole formation (Vera et al., 2011). It is also able to cleave AMA1, and adhesins during parasite invasion. There is no evidence in the literature of parasiteprotein sites for which modifications of phosphorylation intensity have been described. However, the corresponding proteins play a role in iRBC membrane and cytoskeleton remodeling, in order to modify their rigidity and adherence properties. Thus, we can hypothesize that the altered cytoadherence and remodeling of HbAS iRBCs membranes could be linked to the alteration of the phosphorylation status of these proteins. Moreover, our results 
suggest that $\mathrm{HbS}$ is also able to modulate parasite functions. One could also hypothesize that the parasite is able to adapt itself to the different environment of these abnormal RBCs by influencing the phosphorylation balance.

The parasite does not express any classical tyrosine kinase, but only tyrosine kinase-like (Abdi et al., 2013). Numerous studies have demonstrated the importance of the equilibrium in the tyrosine kinase and phosphatase activities during the intra-erythrocytic parasite life. Band 3 was chosen to study the potential Y phosphorylation differences due to HbAS genotype and infection. An increase of Band $3 \mathrm{Y}^{21}$ phosphorylation intensity with infection was observed for HbAA and HbAS donors. However, a decrease of Band $3 \mathrm{Y}^{359}$ phosphorylation intensity with infection was seen for these same donors. The number of donors is low, and we could not exclude individual variation. However, although not statistically detected in MS, the decreased Band $3 \mathrm{Y}^{359}$ phosphorylation intensity appeared to be less important for HbAS donors than for HbAA donors in our western blot analysis. That the reduction of phosphorylation intensity in $\mathrm{HbAS}$ was less than that seen in $\mathrm{HbAA}$ iRBCs at the end of the parasite cycle could regulate Band 3 interactions with other erythrocyte membrane proteins and participate in the deregulation of erythrocyte membrane stability. Indeed, $\mathrm{Y}^{359}$ belongs to the Band 3 binding domain for 4.1 protein (Lux, 2016). Moreover, a recent study suggests that regulation of Band 3 phosphorylation is associated with the erythrocyte membrane destabilization needed for merozoite egress at the end of the intra-erythrocytic cycle (Pantaleo et al., 2017). Variations of Band 3 phosphorylation could be thus associated with altered parasite egress, and could explain the lower parasite replication rate observed in HbAS iRBCs.

Finally, this investigation of the proteome and the phosphoproteome of red cell membrane extracts from $P$. falciparum infected and non-infected erythrocytes, according to HbS heterozygous carriage, allowed us to point out a number of erythrocyte membrane transporters, skeletal proteins and parasite proteins for which phosphorylation was impacted by this genetic abnormality, combined with infection. This study, at the same time novel but also complicated by the use of freshly-collected RBCs, contributes to a better understanding of the biochemical mechanisms involved in conferring protection of HbAS carriers against disease caused by $P$. falciparum.

\section{DATA AVAILABILITY STATEMENT}

The datasets presented in this study can be found in online repositories. The name of the repository/repositories and

\section{REFERENCES}

Abdi, A. I., Carvalho, T. G., Wilkes, J. M., and Doerig, C. (2013). A secreted Plasmodium falciparum kinase reveals a signature motif for classification of tyrosine kinase-like kinases. Microbiol. Read. Engl. 159, 2533-2547. doi: 10.1099/mic.0.070409-0

Archer, N. M., Petersen, N., Clark, M. A., Buckee, C. O., Childs, L. M., and Duraisingh, M. T. (2018). Resistance to Plasmodium falciparum in sickle cell accession number can be found below: ProteomeXchange via the PRIDE database, https://www.ebi.ac.uk/pride/, PXD023280.

\section{ETHICS STATEMENT}

The studies involving human participants were reviewed and approved by Necker-Enfants-Malades Hospital, Committee for the Protection of Persons $\mathrm{n}^{\circ} \mathrm{DC}$ 2014-2272. The patients/ participants provided their written informed consent to participate in this study.

\section{AUTHOR CONTRIBUTIONS}

SA, IG, AL, AM, and FM-N conceived and designed the project. J-AR and SM collected the blood samples. MC, SD, CD, ML, AM, and $\mathrm{MO}$ performed the biochemical experiments. MC, AM, FM$\mathrm{N}$, and DP performed the genotyping. CC, IG, and JL performed the mass spectrometry experiments and analyses. SA, MC, IG, CLVK, AL, AM, and FM-N wrote the paper. All authors reviewed the manuscript before submission. All authors contributed to the article and approved the submitted version.

\section{FUNDING}

We thank the University of Paris for the doctoral scholarship awarded to MC. Funding came partly from the "Laboratoire d'Excellence GR-Ex," Paris, France, reference ANR-11-LABX0051 that is funded by the program "Investissements d'avenir" of the French National Research Agency, reference ANR-11-IDEX0005-02.

\section{ACKNOWLEDGMENTS}

We thank the voluntary blood donors for their participation in this project.

\section{SUPPLEMENTARY MATERIAL}

The Supplementary Material for this article can be found online at: https://www.frontiersin.org/articles/10.3389/fcimb.2021.637604/ full\#supplementary-material

trait erythrocytes is driven by oxygen-dependent growth inhibition. Proc. Natl. Acad. Sci. U. S. A. 115, 7350-7355. doi: 10.1073/pnas.1804388115

Azouzi, S., Collec, E., Mohandas, N., An, X., Colin, Y., and Le Van Kim, C. (2015). The human Kell blood group binds the erythroid 4.1R protein: new insights into the 4.1R-dependent red cell membrane complex. Br. J. Haematol. 171, 862-871. doi: 10.1111/bjh.13778

Azouzi, S., Romana, M., Arashiki, N., Takakuwa, Y., El Nemer, W., Peyrard, T., et al. (2018). Band 3 phosphorylation induces irreversible alterations of stored red blood cells. Am. J. Hematol. 93, E110-E112. doi: 10.1002/ajh.25044 
Badaut, C., Guyonnet, L., Milet, J., Renard, E., Durand, R., Viwami, F., et al. (2015). Immunoglobulin response to Plasmodium falciparum RESA proteins in uncomplicated and severe malaria. Malar. J. 14, 278. doi: 10.1186/s12936015-0799-8

Black, C. G., Proellocks, N. I., Kats, L. M., Cooke, B. M., Mohandas, N., and Coppel, R. L. (2008). In vivo studies support the role of trafficking and cytoskeletal-binding motifs in the interaction of MESA with the membrane skeleton of Plasmodium falciparum-infected red blood cells. Mol. Biochem. Parasitol. 160, 143-147. doi: 10.1016/j.molbiopara.2008.04.001

Bouyer, G., Reininger, L., Ramdani, G., D Phillips, L., Sharma, V., Egee, S., et al. (2016). Plasmodiumfalciparum infection induces dynamic changes in the erythrocyte phospho-proteome. Blood Cells Mol. Dis. 58, 35-44. doi: 10.1016/j.bcmd.2016.02.001

Brandt, G. S., and Bailey, S. (2013). Dematin, a human erythrocyte cytoskeletal protein, is a substrate for a recombinant FIKK kinase from Plasmodium falciparum. Mol. Biochem. Parasitol. 191, 20-23. doi: 10.1016/ j.molbiopara.2013.08.003

Chauvet, M., Tétard, M., Cottrell, G., Aussenac, F., Brossier, E., Denoyel, L., et al. (2019). Impact of Hemoglobin S Trait on Cell Surface Antibody Recognition of Plasmodium falciparum-Infected Erythrocytes in Pregnancy-Associated Malaria. Open Forum Infect. Dis. 6, ofz156. doi: 10.1093/ofid/ofz156

Chishti, A. H., Maalouf, G. J., Marfatia, S., Palek, J., Wang, W., Fisher, D., et al. (1994). Phosphorylation of protein 4.1 in Plasmodium falciparum-infected human red blood cells. Blood 83, 3339-3345.

Cholera, R., Brittain, N. J., Gillrie, M. R., Lopera-Mesa, T. M., Diakité, S. A. S., Arie, T., et al. (2008). Impaired cytoadherence of Plasmodium falciparum-infected erythrocytes containing sickle hemoglobin. Proc. Natl. Acad. Sci. U. S. A. 105, 991-996. doi: 10.1073/pnas.0711401105

Cox, J., Hein, M. Y., Luber, C. A., Paron, I., Nagaraj, N., and Mann, M. (2014). Accurate proteome-wide label-free quantification by delayed normalization and maximal peptide ratio extraction, termed MaxLFQ. Mol. Cell. Proteomics MCP 13, 2513-2526. doi: 10.1074/mcp.M113.031591

Cox, J., and Mann, M. (2008). MaxQuant enables high peptide identification rates, individualized p.p.b.-range mass accuracies and proteome-wide protein quantification. Nat. Biotechnol. 26, 1367-1372. doi: 10.1038/nbt.1511

Cyrklaff, M., Srismith, S., Nyboer, B., Burda, K., Hoffmann, A., Lasitschka, F., et al. (2016). Oxidative insult can induce malaria-protective trait of sickle and fetal erythrocytes. Nat. Commun. 7, 13401. doi: 10.1038/ncomms13401

Dorin-Semblat, D., Tétard, M., Claës, A., Semblat, J.-P., Dechavanne, S., Fourati, Z., et al. (2019). Phosphorylation of the VAR2CSA extracellular region is associated with enhanced adhesive properties to the placental receptor CSA. PloS Biol. 17, e3000308. doi: 10.1371/journal.pbio.3000308

Egan, E. S., Weekes, M. P., Kanjee, U., Manzo, J., Srinivasan, A., Lomas-Francis, C., et al. (2018). Erythrocytes lacking the Langereis blood group protein ABCB6 are resistant to the malaria parasite Plasmodium falciparum. Commun. Biol. 1, 45. doi: 10.1038/s42003-018-0046-2

Esoh, K., and Wonkam, A. (2021). Evolutionary history of sickle cell mutation: implications for global genetic medicine. Hum. Mol. Genet. doi: 10.1093/hmg/ ddab004

Fairhurst, R. M., Bess, C. D., and Krause, M. A. (2012). Abnormal PfEMP1/knob display on Plasmodium falciparum-infected erythrocytes containing hemoglobin variants: fresh insights into malaria pathogenesis and protection. Microbes Infect. Inst. Pasteur 14, 851-862. doi: 10.1016/j.micinf.2012.05.006

Ferru, E., Giger, K., Pantaleo, A., Campanella, E., Grey, J., Ritchie, K., et al. (2011). Regulation of membrane-cytoskeletal interactions by tyrosine phosphorylation of erythrocyte band 3. Blood 117, 5998-6006. doi: 10.1182/blood-2010-11317024

Flint, J., Harding, R. M., Boyce, A. J., and Clegg, J. B. (1998). The population genetics of the haemoglobinopathies. Baillieres Clin. Haematol. 11, 1-51. doi: 10.1016/s0950-3536(98)80069-3

Gelpi, A. P., and King, M. C. (1976). Association of Duffy blood groups with the sickle cell trait. Hum. Genet. 32, 65-68. doi: 10.1007/BF00569977

George, A., Pushkaran, S., Li, L., An, X., Zheng, Y., Mohandas, N., et al. (2010). Altered phosphorylation of cytoskeleton proteins in sickle red blood cells: the role of protein kinase C, Rac GTPases, and reactive oxygen species. Blood Cells Mol. Dis. 45, 41-45. doi: 10.1016/j.bcmd.2010.02.006

Glenister, F. K., Fernandez, K. M., Kats, L. M., Hanssen, E., Mohandas, N., Coppel, R. L., et al. (2009). Functional alteration of red blood cells by a megadalton protein of Plasmodium falciparum. Blood 113, 919-928. doi: 10.1182/blood2008-05-157735

Gonçalves, B. P., Gupta, S., and Penman, B. S. (2016). Sickle haemoglobin, haemoglobin C and malaria mortality feedbacks. Malar. J. 15, 26. doi: $10.1186 / \mathrm{s} 12936-015-1077-5$

Jacob Blackmon, B., Dailey, T. A., Lianchun, X., and Dailey, H. A. (2002). Characterization of a human and mouse tetrapyrrole-binding protein. Arch. Biochem. Biophys. 407, 196-201. doi: 10.1016/s0003-9861(02)00471-x

Kakande, E., Greenhouse, B., Bajunirwe, F., Drakeley, C., Nankabirwa, J. I., Walakira, A., et al. (2020). Associations between red blood cell variants and malaria among children and adults from three areas of Uganda: a prospective cohort study. Malar. J. 19, 21. doi: 10.1186/s12936-020-3105-3

Kariuki, S. N., Marin-Menendez, A., Introini, V., Ravenhill, B. J., Lin, Y.-C., Macharia, A., et al. (2020). Red blood cell tension protects against severe malaria in the Dantu blood group. Nature 585, 579-583. doi: 10.1038/s41586-020-2726-6

Kilili, G. K., Shakya, B., Dolan, P. T., Wang, L., Husby, M. L., Stahelin, R. V., et al. (2019). The Plasmodium falciparum MESA erythrocyte cytoskeleton-binding (MEC) motif binds to erythrocyte ankyrin. Mol. Biochem. Parasitol. 231, 111189. doi: 10.1016/j.molbiopara.2019.111189

Lalle, M., Currà, C., Ciccarone, F., Pace, T., Cecchetti, S., Fantozzi, L., et al. (2011). Dematin, a Component of the Erythrocyte Membrane Skeleton, Is Internalized by the Malaria Parasite and Associates with Plasmodium 14-3-3. J. Biol. Chem. 286, 1227-1236. doi: 10.1074/jbc.M110.194613

Langhi, D. M., and Bordin, J. O. (2006). Duffy blood group and malaria. Hematol. Amst. Neth. 11, 389-398. doi: 10.1080/10245330500469841

Lipecka, J., Chhuon, C., Bourderioux, M., Bessard, M.-A., van Endert, P., Edelman, A., et al. (2016). Sensitivity of mass spectrometry analysis depends on the shape of the filtration unit used for filter aided sample preparation (FASP). Proteomics 16, 18521857. doi: $10.1002 /$ pmic.201600103

Lux, S. E. (2016). Anatomy of the red cell membrane skeleton: unanswered questions. Blood 127, 187-199. doi: 10.1182/blood-2014-12-512772

Mankelow, T. J., Satchwell, T. J., and Burton, N. M. (2012). Refined views of multiprotein complexes in the erythrocyte membrane. Blood Cells Mol. Dis. 49, 1-10. doi: $10.1016 /$ j.bcmd.2012.03.001

Manno, S., Takakuwa, Y., Nagao, K., and Mohandas, N. (1995). Modulation of erythrocyte membrane mechanical function by beta-spectrin phosphorylation and dephosphorylation. J. Biol. Chem. 270, 5659-5665. doi: 10.1074/ jbc. 270.10 .5659

Meijer, B. M., Jang, S. M., Guerrera, I. C., Chhuon, C., Lipecka, J., Reisacher, C., et al. (2017). Threonine eliminylation by bacterial phosphothreonine lyases rapidly causes cross-linking of mitogen-activated protein kinase (MAPK) in live cells. J. Biol. Chem. 292, 7784-7794. doi: 10.1074/jbc.M117.775940

Merckx, A., Nivez, M.-P., Bouyer, G., Alano, P., Langsley, G., Deitsch, K., et al. (2008). Plasmodium falciparum regulatory subunit of cAMP-dependent PKA and anion channel conductance. PloS Pathog. 4, e19. doi: 10.1371/journal.ppat.0040019

Migot-Nabias, F., Mombo, L. E., Luty, A. J., Dubois, B., Nabias, R., Bisseye, C., et al. (2000). Human genetic factors related to susceptibility to mild malaria in Gabon. Genes Immun. 1, 435-441. doi: 10.1038/sj.gene.6363703

Miller, L. H., Baruch, D. I., Marsh, K., and Doumbo, O. K. (2002). The pathogenic basis of malaria. Nature 415, 673-679. doi: 10.1038/415673a

Moiz, B., and Majeed, A. (2018). No risk reduction for Plasmodium vivax malaria in sickle cell disease. Clin. Case Rep. 6, 1187-1188. doi: 10.1002/ccr3.1507

Nunes, M. C., Okada, M., Scheidig-Benatar, C., Cooke, B. M., and Scherf, A. (2010). Plasmodium falciparum FIKK kinase members target distinct components of the erythrocyte membrane. PloS One 5, e11747. doi: 10.1371/ journal.pone.0011747

Okafor, I. M., Okoroiwu, H. U., and Ekechi, C. A. (2019). Hemoglobin S and Glucose-6-Phosphate Dehydrogenase Deficiency Coinheritance in AS and SS Individuals in Malaria-Endemic Region: A Study in Calabar, Nigeria. J. Glob. Infect. Dis. 11, 118-122. doi: 10.4103/jgid.jgid_154_18

Pantaleo, A., De Franceschi, L., Ferru, E., Vono, R., and Turrini, F. (2010a). Current knowledge about the functional roles of phosphorylative changes of membrane proteins in normal and diseased red cells. J. Proteomics 73, 445-455. doi: 10.1016/j.jprot.2009.08.011

Pantaleo, A., Ferru, E., Carta, F., Mannu, F., Giribaldi, G., Vono, R., et al. (2010b). Analysis of changes in tyrosine and serine phosphorylation of red cell membrane proteins induced by P. falciparum growth. Proteomics 10, 34693479. doi: 10.1002/pmic.201000269 
Pantaleo, A., Kesely, K. R., Pau, M. C., Tsamesidis, I., Schwarzer, E., Skorokhod, O. A., et al. (2017). Syk inhibitors interfere with erythrocyte membrane modification during P falciparum growth and suppress parasite egress. Blood 130, 1031-1040. doi: 10.1182/blood-2016-11-748053

Pei, X., Guo, X., Coppel, R., Bhattacharjee, S., Haldar, K., Gratzer, W., et al. (2007). The ring-infected erythrocyte surface antigen (RESA) of Plasmodium falciparum stabilizes spectrin tetramers and suppresses further invasion. Blood 110, 1036-1042. doi: 10.1182/blood-2007-02-076919

Perez-Riverol, Y., Csordas, A., Bai, J., Bernal-Llinares, M., Hewapathirana, S., Kundu, D. J., et al. (2019). The PRIDE database and related tools and resources in 2019: improving support for quantification data. Nucleic Acids Res. 47, D442-D450. doi: 10.1093/nar/gky1106

Piel, F. B., Patil, A. P., Howes, R. E., Nyangiri, O. A., Gething, P. W., Williams, T. N., et al. (2010). Global distribution of the sickle cell gene and geographical confirmation of the malaria hypothesis. Nat. Commun. 1, 104. doi: 10.1038/ ncomms 1104

Rhee, S. G., and Kil, I. S. (2017). Multiple Functions and Regulation of Mammalian Peroxiredoxins. Annu. Rev. Biochem. 86, 749-775. doi: 10.1146/annurevbiochem-060815-014431

Rug, M., Cyrklaff, M., Mikkonen, A., Lemgruber, L., Kuelzer, S., Sanchez, C. P., et al. (2014). Export of virulence proteins by malaria-infected erythrocytes involves remodeling of host actin cytoskeleton. Blood 124, 3459-3468. doi: 10.1182/blood-2014-06-583054

Taylor, S. M., Cerami, C., and Fairhurst, R. M. (2013). Hemoglobinopathies: slicing the Gordian knot of Plasmodium falciparum malaria pathogenesis. PloS Pathog. 9, e1003327. doi: 10.1371/journal.ppat.1003327

Trager, W., and Jensen, J. B. (1976). Human malaria parasites in continuous culture. Science 193, 673-675. doi: 10.1126/science.781840
Tyanova, S., Temu, T., Sinitcyn, P., Carlson, A., Hein, M. Y., Geiger, T., et al. (2016). The Perseus computational platform for comprehensive analysis of (prote)omics data. Nat. Methods 13, 731-740. doi: 10.1038/nmeth.3901

Vera, I. M., Beatty, W. L., Sinnis, P., and Kim, K. (2011). Plasmodium protease ROM1 is important for proper formation of the parasitophorous vacuole. PloS Pathog. 7, e1002197. doi: 10.1371/journal.ppat.1002197

Waller, K. L., Nunomura, W., An, X., Cooke, B. M., Mohandas, N., and Coppel, R. L. (2003). Mature parasite-infected erythrocyte surface antigen (MESA) of Plasmodium falciparum binds to the $30-\mathrm{kDa}$ domain of protein 4.1 in malariainfected red blood cells. Blood 102, 1911-1914. doi: 10.1182/blood-2002-113513

Waller, K. L., Stubberfield, L. M., Dubljevic, V., Buckingham, D. W., Mohandas, N., Coppel, R. L., et al. (2010). Interaction of the exported malaria protein Pf332 with the red blood cell membrane skeleton. Biochim. Biophys. Acta 1798, 861-871. doi: 10.1016/j.bbamem.2010.01.018

Conflict of Interest: The authors declare that the research was conducted in the absence of any commercial or financial relationships that could be construed as a potential conflict of interest.

Copyright (C) 2021 Chauvet, Chhuon, Lipecka, Dechavanne, Dechavanne, Lohezic, Ortalli, Pineau, Ribeil, Manceau, Le Van Kim, Luty, Migot-Nabias, Azouzi, Guerrera and Merckx. This is an open-access article distributed under the terms of the Creative Commons Attribution License (CC BY). The use, distribution or reproduction in other forums is permitted, provided the original author(s) and the copyright owner(s) are credited and that the original publication in this journal is cited, in accordance with accepted academic practice. No use, distribution or reproduction is permitted which does not comply with these terms. 